\title{
BMJ Open Scoping review protocol to understand the conceptualisation, implementation and practices of health promotion within the context of primary healthcare in Africa
}

\author{
Miriam Nkangu (D) ,, ${ }^{1,2}$ Pamela Obegu, ${ }^{2}$ Constantine Asahngwa, ${ }^{2,3}$ \\ Veronica Shiroya, ${ }^{4,5}$ Ronald Gobina, ${ }^{2,3}$ Fleur Pembe Agbaw-Ebai, ${ }^{2,6}$ Mark Keboa, ${ }^{2}$ \\ Denis Foretia ${ }^{3,7}$
}

To cite: Nkangu M, Obegu P, Asahngwa C, et al. Scoping review protocol to understand the conceptualisation, implementation and practices of health promotion within the context of primary healthcare in Africa. BMJ Open 2021;11:e049084. doi:10.1136/ bmjopen-2021-049084

- Prepublication history and additional supplemental material for this paper are available online. To view these files, please visit the journal online (http://dx.doi.org/10.1136/ bmjopen-2021-049084).

Received 21 January 2021 Accepted 11 November 2021

Check for updates

(C) Author(s) (or their employer(s)) 2021. Re-use permitted under CC BY-NC. No commercial re-use. See rights and permissions. Published by BMJ.

For numbered affiliations see end of article.

Correspondence to

Miriam Nkangu;

mnkangu@alliancehp.org

\section{ABSTRACT}

Introduction The ongoing COVID-19 pandemic has highlighted the importance of health promotion in empowering and sustaining communities, as well as the need to build resilient health systems and work collectively with other sectors to protect and promote health. The WHO has mainstreamed health promotion in the Global health agenda. However, the definition and practices of health promotion in Africa are not well understood and documented, with often, an interchangeable use of the concept of health promotion and health prevention. This scoping review is to explore how health promotion is defined and practised in Africa and identify gaps in its implementation within the framework of the Ottawa Charter.

Methods and analysis The scoping review will employ the approach described by Arksey and 0'Malley in 2005 . The approach consists of five stages: (1) formulating the research questions, (2) identifying relevant studies, (3) selecting eligible studies, (4) charting the data and (5) collating, summarising and reporting the results. This protocol employed the Preferred Reporting Items for Systematic Reviews and Meta-Analysis Protocols (PRISMA-P). The review will apply the PRISMA extension for scoping reviews to present the results. The scoping review will adapt the five principles set forth in the 0ttawa Charter to categorise the outcomes and uses its strategies to define the interventions. Data bases searched are Ovid Medline, Embase, Cochrane Library, CINAHL, SCOPUS, $\mathrm{CABI}$, JBI Evidence Synthesis and grey literature. The database last searched was January 2021.

Ethics and dissemination This review does not require ethics approval. Our dissemination strategy includes peer review publication, policy brief, presentation at conferences and relevant stakeholders.

\section{INTRODUCTION}

Health promotion (HP) is a 'behavioural social science that draws from the biological, environmental, psychological, physical, and medical sciences to promote health and

\section{Strength and limitations of this study}

- This is a novel scoping review to understand how health promotion is conceptualised, defined and practised in Africa within the context of the principles of the Ottawa Charter.

- This review will be extended to inform case study research for a specific country.

- Stakeholders and health promotion practitioners will be consulted throughout the study.

- This review will be limited to publications in selected languages included in the review; this may bias some of the studies that maybe published in other language not included in this review.

prevent disease, disability, and premature death through education-driven voluntary behaviour change activities'. "The Ottawa Charter defines HP as 'the process of enabling people and groups to increase control over and to improve their health and quality of life'. ${ }^{2}$ HP involves the development of individual, group, institutional, community and systemic strategies to improve health knowledge, attitudes, skills and behaviour. ${ }^{3}$ These factors extend beyond the social determinants of health $(\mathrm{SDH})$, to include economical, environmental, political and cultural; they not only impact health but can also either make it easier or more difficult for individuals to make changes that improve their health. ${ }^{45}$ HP's role is in helping to improve these SDH by targeting people at the individual level to change their behaviours. ${ }^{1-5}$ It is a comprehensive approach that addresses a broad spectrum of health factors and determinants to foster healthy lifestyle choices. ${ }^{1-5} \mathrm{HP}$ also involves the dissemination of information using various channels of communication in 
order to increase health knowledge and social mobilisation. ${ }^{6}$ Therefore, HP is not only the responsibility of the health sector but extends beyond promoting healthy lifestyles to improved well-being. ${ }^{2}$ The WHO defines health as a complete state of physical, mental and social wellbeing rather than just the absence of disease. ${ }^{78} \mathrm{HP}$ is an approach within primary healthcare that seeks to support and build an understanding of the determinants of health and develop personal skills to improve one's health and well-being. ${ }^{4-8}$

Primary healthcare is critical in every healthcare system in improving the delivery of care and health outcomes. ${ }^{8}$ However, there is no universally accepted definition on primary healthcare, while it is seen as the first level of care in most high-income countries, in most low and middle-income countries, it is more of a system wide approach. ${ }^{8-10}$ This review will apply the conceptual definition of primary healthcare which "refers to both processes and beliefs about the ways in which healthcare is structured encompassing primary care, disease prevention, health promotion, population health, and community development within a holistic framework, with the aim of providing essential community-focused health care" 910

In recent decades, the concept of HP has received increasing global attention. In 1986, the first international conference was organised by the WHO in Ottawa, Canada, which led to the creation of the Ottawa Charter. ${ }^{2}$ This Charter is a landmark document and has been influential in informing the conceptualisation, goals and implementation of HP. ${ }^{2-8}$ The principles of HP set forth in this Charter are still used as a reference document to guide theory and practice. ${ }^{1-8}$ The Charter presents five action areas: design healthy public policy, create supportive environments, strengthen community actions, develop personal skills and reorient health services (discussed in details in stage 5 and table 1 ).$^{2-5}$ Further, the Charter discussed three strategies to improve health which includes, enabling-creating an enabling environment, mediating and advocating - to improve health. ${ }^{2-5}$

A series of global HP conferences have been convened by the WHO calling for collective efforts to improve the health of the population. ${ }^{6}{ }^{11}$ In addition to these conferences, the World Health Assembly adopted resolution WHA51.12 on HP; ${ }^{6}{ }^{12}$ resolution WHA57.16 on HP and lifestyles; ${ }^{6} 13$ resolution WHA60.24 on HP in a globalised world; ${ }^{6}{ }^{14}$ and the Nairobi Call to Action for closing the implementation gap in HP (2009), ${ }^{615}$ as well as political declarations on SDH and non-communicable diseases. ${ }^{16}{ }^{17}$ However, despite these progress, in 2013, the WHO Africa region identified the existence of significant gaps and challenges in HP especially in areas of stewardship, delivery of interventions, community participation and empowerment, evidence generation and sustainable financing. ${ }^{6}$

The ongoing COVID-19 pandemic has highlighted the importance of HP in empowering and sustaining

Table 1 Application of the Ottawa Charter principles on the outcomes

\begin{tabular}{|c|c|}
\hline Principles & Explanations and examples as applicable \\
\hline $\begin{array}{l}\text { Strengthen } \\
\text { community } \\
\text { actions }\end{array}$ & $\begin{array}{l}\text { This will identify what is happening at sub national and community level, which organisations are involved and } \\
\text { what are they most focused on for example, Non comunicable diseases (NCD), mental health, HIV, COVID-19 } \\
\text { and what strategies are mostly used? Are community and community health workers engaged? is it a multi } \\
\text { sectoral approach? What collective actions or approaches are used? Are the organisations and the actions } \\
\text { government funded or rely on development funding? are they linked with the health system and existing } \\
\text { structures or work in parallel? }\end{array}$ \\
\hline $\begin{array}{l}\text { Reorient health } \\
\text { services }\end{array}$ & $\begin{array}{l}\text { This will identify the focus of existing services in terms of: are they mostly traditional focused, is it left within } \\
\text { the confines of hospitals, schools, communities, health centres? Does it take a holistic approach? Is it gender } \\
\text { and culturally sensitive? how is the health system organised? Do they have community health strategies, } \\
\text { documents, and frameworks? How is the care organised, does it focus on curative or incorporates HP } \\
\text { aspects, are they mediating (collaborating) with other sectors in an effort to address some underlying risk } \\
\text { factors and aspects of social determinants of health? }\end{array}$ \\
\hline
\end{tabular}

Source: Adapted from the Ottawa Charter 1986, Kessler C et al., 2011.

$\mathrm{HP}$, health promotion. 
communities, as well as the need to build resilient health systems and work collectively with other sectors to protect public health. The concept of HP is highly relevant in Africa given the continent's poor health outcomes. ${ }^{18-24}$ Though HP activities in Africa have received some significant development in the last decades ${ }^{19}$ Africa still lags behind in adopting a comprehensive approach to HP. ${ }^{19-25}$ HP activities conducted in Africa have focused more on health education. ${ }^{18-24}$ One of the underlying reasons documented in the literature related to some African countries' inability to fully adopt the concept of HP relates to the limited participation of African countries in HP meetings ${ }^{20-25}$; thus, conceptualisation may likely be perceived and practised differently. In this light, most HP activities are focused on health education, and the concept of HP is often reduced to disease prevention. ${ }^{19-25}$

The WHO and its global partners recently mainstreamed HP in global health and issued a call to action for countries to invest in HP to ensure sustainable health systems. ${ }^{26}$ In addition, the WHO is working on developing a global strategy for HP, and the current pandemic has demonstrated the dire need for HP to support communities and systems in becoming more resilient in addressing epidemics and pandemics. Based on these action plans, there is a need to understand how HP is defined and practised in African countries, as well as comprehensively understand the state of HP in Africa within the context of the Ottawa Charter and gaps in its implementation. Thus, our scoping review builds on understanding how HP is defined, conceptualised, implemented and practised within the context of primary healthcare in Africa. We aim to map out the action areas of HP activities in Africa and identify key gaps within the framework of the Ottawa Charter. A scoping review is suited for our topic due to the limited amount of published evidence in this area as most information may be documented as grey literature, a scoping review will help understand the breadth and depth of HP in Africa, how the concept is defined, perceived and practised. In addition, scoping review is best for concept mapping to identify knowledge gaps and the main sources and types of evidence that exist on HP in Africa. ${ }^{27}$

\section{METHOD}

\section{Protocol design}

The scoping review employs an approach described by Arksey and O'Malley. ${ }^{28}$ The approach consists of five stages: (1) formulating the research questions, (2) identifying relevant studies, (3) selecting eligible studies, (4) charting the data and (5) collating, summarising and reporting the results. The scoping review also draws inspiration from methodology developed by the Joanna Briggs Institute. ${ }^{29}$ The protocol is not registered with PROSPERO, as it currently does not accept scoping reviews. We used the Preferred Reporting Items for Systematic Reviews and Meta-Analysis Protocols (PRISMA-P) ${ }^{30}$ to prepare the protocol and we will use the PRISMA-ScR extension for scoping reviews to present the results.

\section{Patient and public involvement}

No patients were involved in the review protocol. However, the public was involved in defining the research questions using informal discussions with some stakeholders and health professionals. We used a team of researchers and HP practitioners to inform this process using a miniDelphi approach as we discussed the review. The review is the first stage of our research. An in-depth follow-up study will be conducted as a case study in Cameroon and Kenya which will include secondary data analysis, a workshop, interviews and stakeholder consultations on how the concept of HP is defined, practised and implemented in Cameroon and Kenya within the context of the Ottawa Charter. The workshop and qualitative study will allow us to engage with a broad team from different sector, health providers, including community health workers, selected communities and relevant stakeholders from various sectors, to explore their perspective, understanding and definition of HP in Cameroon and Kenya.

\section{Stage 1: formulating the research question}

We used an iterative process, as recommended by Arksey and O'Malley, to develop the research question through consultations with the research team and other public and HP practitioners. The main research question focuses on understanding how HP is defined and practised in the context of primary healthcare in Africa, within the framework of the Ottawa Charter, as well as on identifying and characterising the gaps. Our primary study and workshop will follow this approach. The following questions will guide the review:

1. How is HP defined and conceptualised within the context of primary healthcare in Africa?

2. What are the identified strategies and/or approaches of HP that are implemented and/or practised within the context of primary healthcare in Africa and as categorised within the framework of the Ottawa Charter? 3. What are the gaps, limitations and opportunities?

\section{Stage 2: identifying relevant studies}

The search includes studies conducted from 1986 to the present, as this range includes the creation of the Ottawa Charter. $^{2}$ All relevant databases will be searched with the help of a librarian. These databases include but are not limited to Ovid Medline, Embase, Cochrane Library, CABI Global Health (Ovid), CINAHL, SCOPUS and JBI Evidence Synthesis. Both published and grey literature will be searched, and we will contact relevant stakeholders for additional grey literature where applicable. Grey literature will be searched from the WHO database, Department for International Development research outputs database and the ELDIS development database (eldis. org), Africa Center for Disease Control, Africa Center for Evidence, Africa Academy of Science. Additionally, the reference list of potential eligible papers will be 


\begin{tabular}{|c|c|c|}
\hline & $\begin{array}{l}\text { Inclusion } \\
\text { criteria }\end{array}$ & $\begin{array}{l}\text { Exclusion } \\
\text { criteria }\end{array}$ \\
\hline \multicolumn{3}{|l|}{ Sources } \\
\hline Focus & $\begin{array}{l}\text { Studies or reports on health } \\
\text { promotion, definition, practice } \\
\text { and implementation } \\
\text { No limit }\end{array}$ & \\
\hline Context & African context & $\begin{array}{l}\text { Non-African } \\
\text { countries or } \\
\text { context }\end{array}$ \\
\hline Language & $\begin{array}{l}\text { English, French, German and } \\
\text { Swahili }\end{array}$ & $\begin{array}{l}\text { Other } \\
\text { languages }\end{array}$ \\
\hline Year & Year limit from 1986 & Before 1986 \\
\hline
\end{tabular}

hand-searched. The results will be exported to Endnote and later exported to Covidence software ${ }^{31}$ for title and abstract screening. Articles will be included if they meet our inclusion criteria and excluded if they do not meet the criteria. The initial search terms used MeSH terms related to HP and primary healthcare and key words using Ovid Medline platform and will be further adapted to other databases (see online supplemental file 1). In order for a study to be included in this review, the study will meet the following inclusion and exclusion criteria as described in table 2. Additionally, a description of the PICO (population, intervention, comparators and outcomes) elements is outlined below to guide the screening and identification of relevant studies.

Type of population: primary healthcare settings-this is based on the definition of PHC above which extends to communities and schools.

Types of intervention: the intervention is focused on any HP implementation strategies to improve health and well-being. The interventions are categorised, when applicable, using the three strategies described by the Ottawa Charter: advocate, mediate and enable. Advocacy requires a combination of individual and social actions to obtain political commitment, policy support and social systems that support health. ${ }^{2}$ Mediation is the process by which different interests of individuals, communities and other sectors, both public and private, work together in a way that promotes and protects health. ${ }^{2}$ Enabling ensures that HP activities designed to improve health are in partnership with individuals to enable and empower them to take action to protect and promote health. ${ }^{2}$

Comparator: any active or inactive comparators

Types of outcomes: outcomes will be categorised and described within the framework of the five principles of the Ottawa Charter. Any of the listed outcomes below to improve health and well-being adopted from the WHO Africa region. ${ }^{6}$ This includes increased community awareness on health, participation, empowerment, positive behaviour changes, changes in societal structures, programmes, evidence-based policies and legislations. ${ }^{6}$ This will be discussed and categorised in relation to the five principles listed in table 1 . The Ottawa Charter framework will be used to guide our analysis and categorise the outcome definition, scope and literature across multiple contexts and strategies that consider both the individual and community in delivering HP in Africa.

\section{Stage 3: selecting studies}

The search results will be exported into Endnote for data management (eg, removing duplicates and referencing). After removing duplicates, data will be exported into Covidence for screening and data extraction. Title and abstract screening will be done by two pairs of independent reviewers to select studies related to our population, intervention, comparators and outcomes (PICO) format as described above. The second stage includes full-text screening. This will be done by two pairs of independent reviewers selecting studies that meet our inclusion criteria. Studies that potentially meet the inclusion criteria will be retrieved in full text during this stage of screening. Fulltext studies that do not meet the inclusion criteria will be excluded, and the reasons for exclusion will be provided in the final report. Data will be extracted by two pairs of independent reviewers and inter-rater reliability will be assessed and discussed against the themes. The final results of the search will be reported in full in the final report and presented in a PRISMA flow diagram. Disagreements that arise between the reviewers will be resolved through discussion or with a third reviewer. Understanding of the inclusion and exclusion criteria will be assessed through the calibration of a few studies adhering strictly to the PICO criteria. Disagreements will be resolved through consensus; if consensus is not achieved, a third reviewer (ie, a coauthor) will be consulted. If a study has multiple publications, the most recent one will be retained. At this stage, the language is limited to French, English, Swahili and German.

\section{Stage 4: extracting data}

A data extraction form adopted from Joanna Briggs Institute's template for data extraction (see table 3) ${ }^{29}$ will be used. Key information will be collected from the relevant studies: publication year, country and context, design, conceptual framework used, objective, methods and study findings. The form will be used to collect data on the intervention strategies (ie, mediating, enabling or advocating), and outcomes will be categorised according to each component of the Ottawa Charter and data for this component will be extracted as described in table 1 . To ensure the validity of the process, the form will be piloted and tested against a few studies by MN, VS and MK and discussed with other coauthors. Two pairs of independent reviewers will then extract the data, and disagreements will be resolved through consensus among the team members. A quality appraisal of the primary studies included in the review will be assessed using the Critical Appraisal Skills Programme tool developed at Oxford University, ${ }^{32}$ and for mixed-method studies, a tool developed by Pluye $e t a l^{33}$ will be used. 
Table 3 Data extraction tool

\begin{tabular}{|c|c|c|}
\hline Dimensions & Details & Additional explanation as applicable \\
\hline $\begin{array}{l}\text { General } \\
\text { information }\end{array}$ & Authors, year, country of study, language, funder & \\
\hline $\begin{array}{l}\text { Study } \\
\text { participants }\end{array}$ & $\begin{array}{l}\text { Description of study population, characteristics of study participants, } \\
\text { recruitment strategies, sampling and sample size, age }\end{array}$ & \\
\hline $\begin{array}{l}\text { Implementation } \\
\text { strategies or } \\
\text { intervention }\end{array}$ & $\begin{array}{l}\text { Description of the intervention in relation to the health promotion } \\
\text { strategies, intervention groups or populations, types of interventions }\end{array}$ & $\begin{array}{l}\text { Health promotion strategies (enabling, } \\
\text { mediating, advocating). }\end{array}$ \\
\hline Data analysis & $\begin{array}{l}\text { Identify and code the activities or intervention strategies and } \\
\text { categorise them according to the three listed strategies (mediating, } \\
\text { enabling, advocating) in addition to any other approach that does not } \\
\text { fall within the three strategies. }\end{array}$ & \\
\hline $\begin{array}{l}\text { Equity } \\
\text { dimensions }\end{array}$ & $\begin{array}{l}\text { Dimensions using variables from PROGRESS framework }{ }^{34} \text { (place, } \\
\text { religion, occupation, gender, race, education, social capital and } \\
\text { socio-economic status) as applicable }\end{array}$ & $\begin{array}{l}\text { Any of the PROGRESS-plus } \\
\text { variables considered in the } \\
\text { intervention population and/or } \\
\text { groups - place (rural or urban setting), } \\
\text { occupation, education, income status } \\
\text { and so on towards addressing social } \\
\text { determinants of health variables }\end{array}$ \\
\hline $\begin{array}{l}\text { Context } \\
\text { characteristics }\end{array}$ & Primary healthcare setting, community, schools & $\begin{array}{l}\text { Description and or definition of the } \\
\text { primary healthcare setting }\end{array}$ \\
\hline
\end{tabular}

\section{Stage 5: collating, summarising and reporting the outcomes}

In this stage, the scoping review will provide an aggregated synthesis of the evidence employing the five components of the Ottawa Charter (as listed in table 1) to discuss the outcomes (as listed in stage 2), grouping results by country experiences as reported in the studies. The five components include healthy public policies defined by the Charter as the process of setting policies that support health by protecting the health of individuals and communities and making it easier for people to make healthy choices. The environment in which people live, both natural and built (eg, communities, workplaces and schools), is closely linked to health. ${ }^{1-8}$ These environments also determine and increase the ability of people to make healthy choices while living or being exposed to these environments. ${ }^{4-8}$ The collective effort of communities to improve public health can involve various groups, for example, community-based organisations that support people living with HIV/AIDs, diabetes and other related diseases. ${ }^{1-8}$ Developing skills focused on personal and social developmen-building capacity and health literacy through education and information enhances the life skills of individuals and helps them make positive choices, ${ }^{1-8}$ for example, providing information, education, distributing educational materials, workshops, training and sessions that teach people how to manage diseases. ${ }^{1-8}$ Reorienting health services-moving from traditionally medical focused individual and curative needs to people and community-health services focusing on protective factors, holistic approach, reducing risk factors and improving on the $\mathrm{SDH} .^{2-5}$

Descriptive analysis will be performed, and similar data segments will be pooled, and deductive codes in line with the outcomes will be extracted and coded and interrater reliability will be assessed. The data collected from the included studies will be tabulated and summarised narratively. The scoping review will also present our experiences and recommendations to inform policies and the HP community.

\section{Limitations}

This review is limited to all African countries, and therefore, the scope does not include other low-income and middle-income countries. This review may suffer from publication bias, which is why we chose a scoping review approach. The review is also limited to selected languages which may bias the evidence.

\section{CONCLUSION}

Fundamentally, HP attempts to address inequalities. ${ }^{18-24}$ Addressing universal healthcare coverage and leaving no one behind require a collective effort. HP initiatives are relevant in Africa, but there is a need to understand and 
appreciate the available evidence and identify the gaps and approaches to inform policy. This review will generate evidence to guide research and inform policies. The results could assist development organisations, governments and other stakeholders to identify priority areas for HP strategies. In the results and discussion sections, we will identify any similarities and/or differences between approaches adopted in Africa and the Ottawa Charter.

\section{ETHICS AND DISSEMINATION}

This review does not require ethics approval. Our dissemination strategy includes peer review publication, policy brief, presentation at conferences and relevant stakeholders.

\section{Author affiliations}

${ }^{1}$ School of Epidemiology and Public Health, University of Ottawa Faculty of

Medicine, Ottawa, Ontario, Canada

${ }^{2}$ Research and Capacity Building, Health Promotion Alliance Cameroon (HPAC), Yaounde, Cameroon

${ }^{3}$ Nkafu Policy Institute, Denis and Lenora Foretia Foundation Cameroon, Yaounde, Cameroon

${ }^{4}$ Health Promotion Alliance Kenya, Kitale, Kenya

${ }^{5}$ Institute of Global Health, Heidelberg University, Heidelberg, Baden-Württemberg, Germany

${ }^{6}$ University of Bamenda, Bambili, NW Region, Cameroon

${ }^{7}$ Center for Muliticultural and Global Health, University of Tennessee Health Science Center, Memphis, Tennessee, USA

Acknowledgements The authors specifically thank Lindsey Sikora for assisting in the search strategy, Bernand Kadasia, Gabriella Sozanski, and Jean-Pierre Girard for their feedback and guidance and the entire team at Health Promotion Alliance Cameroon and the Nkafu Policy Institute for their feedback on the research questions.

Contributors MN conceived the idea for the scoping review. MN led the design of the protocol and methodology and wrote the first draft of the manuscript. MK, MN, VS provided inputs to the methods, designed the search strategy and critically revised the manuscript. MN, VS and PO designed the data extraction form. FPA-E, $\mathrm{RG}, \mathrm{CA}$ and $\mathrm{DF}$ supervised the public involvement and provided additional inputs on the research questions. All authors provided valuable inputs to the research questions and subject matter.

Funding The authors have not declared a specific grant for this research from any funding agency in the public, commercial or not-for-profit sectors.

Competing interests None declared.

Patient consent for publication Not applicable.

Provenance and peer review Not commissioned; externally peer reviewed.

Supplemental material This content has been supplied by the author(s). It has not been vetted by BMJ Publishing Group Limited (BMJ) and may not have been peer-reviewed. Any opinions or recommendations discussed are solely those of the author(s) and are not endorsed by BMJ. BMJ disclaims all liability and responsibility arising from any reliance placed on the content. Where the content includes any translated material, BMJ does not warrant the accuracy and reliability of the translations (including but not limited to local regulations, clinical guidelines, terminology, drug names and drug dosages), and is not responsible for any error and/or omissions arising from translation and adaptation or otherwise.

Open access This is an open access article distributed in accordance with the Creative Commons Attribution Non Commercial (CC BY-NC 4.0) license, which permits others to distribute, remix, adapt, build upon this work non-commercially, and license their derivative works on different terms, provided the original work is properly cited, appropriate credit is given, any changes made indicated, and the use is non-commercial. See: http://creativecommons.org/licenses/by-nc/4.0/.

\section{ORCID iD}

Miriam Nkangu http://orcid.org/0000-0001-8039-9979
REFERENCES

1 Kessler C, Renggli V. Health promotion: concepts and practices. A key issue paper focusing on the relevance for international cooperation. Swiss Agency for Development and Cooperation, 2011.

2 Ottawa charter for health promotion, 1986. Available: http://www. who.int/hpr/NPH/docs/ottawacharterhp.pdf

3 Jackson SF, Perkinsi F, Khandor E. Integrated health promotion strategies: a contribution to tackling current and future health challenges. Health Promotion International 2007;21.

4 Marmot M, Allen JJ. Social determinants of health equity. Am J Public Health 2014;104 Suppl 4:S517-9.

5 Commission on Social Determinants of Health. CSDH final report: closing the gap in a generation: health equity through action on the social determinant of health. Geneva, Switzerland: World Health Organization, 2008.

6 World Health Organization Health Promotion strategy for the African region. Regional office for Africa, Brazzaville, 2013.

7 World Health Organization. Conference working documents. A primer for Mainstreaming health promotion, 2009. Available: http://www.who.int/ healthpromotion/conferences/7gchp/documents/en/index5.html

8 World Health Organization. Conference working documents. Mainstreaming health promotion: a practical toolkit, 2009. Available: http://www.who.int/healthpromotion/conferences/7gchp/documents/ en/index6.html

9 Bresick G, Christians F, Makwero M, et al. Primary health care performance: a scoping review of the current state of measurement in Africa. BMJ Glob Health 2019;4:e001496. 10.1136/ bmjgh-2019001496:e001496.

10 Shoultz J, Hatcher PA. Looking beyond primary care to primary health care: an approach to community-based action. Nurs Outlook 1997;45:23-6.

11 WHO. Milestones in health promotion: statements from global conferences, 2009. Available: https://www.who.int/healthpromotion/ Milestones_Health_Promotion_05022010.pdf [Accessed 09 Aug 2021].

12 Resolution. WHA51.12: health promotion. Available: http://ldb.org/vl/ top/wha51.htm [Accessed 09 Aug 2021].

13 Resolution. WHA57.16: health promotion and healthy lifestyles. Available: http://apps.who.int/iris/bitstream/handle/10665/20141/ A57_R16-en.pdf?sequence=1 [Accessed 09 Aug 2021].

14 Resolution. WHA60.24: health promotion in a globalized world. Available: https://apps.who.int/iris/bitstream/handle/10665/22599/ A60_R24-en.pdf?sequence=1\&isAllowed=y [Accessed 9 Aug 2021].

$15 \mathrm{WHO}$. The Nairobi call to action for closing the implementation gap in health promotion. Nairobi, Kenya: 7th Global Conference on Health Promotion, 2009. https://www.who.int/teams/health-promotion/ enhanced-wellbeing/seventh-global-conference

16 WHO: Rio political Declaration on social determinants of health. world conference on social determinants of health, Rio de Janeiro, Brazil: 19-21 October, 2011. Available: https://www.who.int/sdhconference/ declaration/Rio_political_declaration.pdf [Accessed 10 Aug 2021].

17 UN. UN: political Declaration of the high level meeting of the general assembly on the prevention and control of noncommunicable diseases. 16. New York, 2011. https://digitallibrary.un.org/record/ $710899 / ? \ln =e n$

18 World Health Organization. Primary health care, 1978. Available: http://whqlibdoc.who.int/publications/1978/9241541288_eng.pdf [Accessed 20 Nov 2020].

19 AlHD I. Evidence of health promotion effectiveness in Africa. edited by Mary Amuyunzu-Nyamongo and David Nyamawa, 2010. Available: http://www.iuhpe.org/admin/uploaded/Publications/Books Reports/Evidence HPEffectiveness Africa.pdf

20 Nyamwaya D. Health promotion in Africa: strategies, players, challenges and prospects. Health Promot Int 2003;18:85-7.

21 Houéto D. La promotion de la santé en Afrique subsaharienne : état actuel des connaissances et besoins d'actions. Promot Educ 2008;15:49-53.

22 Govender RD. The barriers and challenges to health promotion in Africa. South African Family Practice 2005;47:39-42.

23 Nyamwaya D. Trends and factors in the development of Health Promotion in Africa, 1973-2003. In: Scriven A, Garman S, eds. Promoting health, global perspectives. Londres: Palgrave, 2005: 167-78.

24 Sanders D, Stern R, Struthers P, et al. What is needed for health promotion in Africa: band-aid, live aid or real change? Crit Public Health 2008;18:509-19.

25 Ndjepel J, Ngangue P, Mballa EE. VII. promotion de la santé au cameroun : état des lieux et perspective 2014/HS S1 | pages 3538 ISSN 0995-3914.

26 World Health Organization. Health promotion a critical pathway to universal health coverage, 9th global forum on health promotion 2019, 2020. 
27 Munn Z, Peters MDJ, Stern C, et al. Systematic review or scoping review? guidance for authors when choosing between a systematic or scoping review approach. BMC Med Res Methodol 2018;18:143.

28 Arksey H, O'Malley L. Scoping studies: towards a methodological framework. Int J Soc Res Methodol 2005;8:19-32.

29 Peters MDJ, Godfrey C, Mclnerney P. Chapter 11: Scoping Reviews (2020 version). In: Aromataris E, Munn Z, eds. JBI manual for evidence synthesis, JBI, 2020.

30 Moher D, Shamseer L, Clarke M, et al. Preferred reporting items for systematic review and meta-analysis protocols (PRISMA-P) 2015 statement. Syst Rev 2015;4:1
31 Covidence systematic review management software. Available: https://www.covidence.org/ [Accessed 20 Nov 2020].

32 Oxford University. Critical appraisal skills programme (CASP), 2013. Available: http://www casp-uk.net/

33 Pluye P, Robert E, Cargo M. Proposal: a mixed methods appraisal tool for systematic mixed studies reviews, 2011. Available: http:// mixedmethodsappraisaltoolpublic.pbworks.com

34 O'Neill J, Tabish H, Welch V, et al. Applying an equity lens to interventions: using progress ensures consideration of socially stratifying factors to illuminate inequities in health. J Clin Epidemiol 2014;67:56-64. 